\title{
MATERNAL AND PERINATAL OUTCOME IN ECLAMPSIA AT A TEACHING HOSPITAL OF EASTERN NEPAL
}

\author{
Mishra $S K^{1^{*}}$, Pradhan $R^{2}$, Pokharel $H P^{3}$, Parajuli $S P^{4}$
}

\section{Affiliation}

1. Lecturer, Department of Obstetrics and Gynaecology, Birat Medical College and Teaching Hospital, Nepal

2 Lecturer, Department of Anaesthesia and critical care, Birat Medical College and Teaching Hospital

3. Professor, Department of Obstetrics and Gynaecology, Birat Medical College and Teaching Hospital, Nepal

4. Assistant Professor, Department of Community medicine, Birat Medical College and Teaching Hospital, Nepal

\section{ARTICLE INFO}

Received : 17 March, 2020
Accepted : 22 November, 2020
Published : 22 December, 2020

(C) Authors retain copyright and grant the journal right of first publication with the work simultaneously licensed under Creative Commons Attribution License CC - BY 4.0 that allows others to share the work with an acknowledgment of the work's authorship and initial publication in this journal.

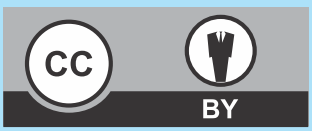

\section{ORA 204}

DOI: https://doi.org/10.3126/bjhs.v5i3.33692

\section{* Corresponding Author \\ Dr. Seema Kumari Mishra Lecturer}

Department of Obstetrics and Gynaecology Birat Medical College \& Teaching Hospital, Nepal

Email ID: drseemamishra506@gmail.com ORCID ID: https://orcid.org/0000-0002-3793-0848

\section{Citation}

Mishra SK, Pradhan R, Pokharel HP, Parajuli SP. Maternal and Perinatal Outcome in Eclampsia at A Teaching Hospital of Eastern Nepal. BJHS 2020;5(3)13. 1186-1190.

\section{ABSTRACT \\ Introduction}

Eclampsia is a multisystem disorder with potential lifethreatening complications that can result in significant maternal and fetal morbidity and mortality. The case fatality rate of eclampsia is $1.8 \%$ in developed countries, $17.7 \%$ in India and $13 \%$ in Nepal. The incidence of pre-eclampsia and eclampsia is high in developing countries due to hypoproteinemia, malnutrition and poor obstetric facilities.

\section{Objective}

To assess the maternal and perinatal outcome in patients of eclampsia

\section{Methodology}

This was a hospital based cross-sectional study where all the patients presenting with eclampsia from June 2019 to November 2020 in the Department of Obstetrics \& Gynecology, Birat Medical College and Teaching Hospital were enrolled for the study. Data analyzed included various maternal parameters and fetal parameters along with the mode of delivery, outcome of baby, postpartum maternal condition and maternal mortality.

\section{Result}

Among 6631 deliveries, 50 patients had eclampsia with the incidence of 7.54/1000 deliveries. Thirty four (68\%) patients were of $20-30$ years of age, 37 (74\%) were primigravidas, 36 (72\%) from rural areas, 34 (68\%) were illiterate, $49(98 \%)$ were poor to average socioeconomic status, 41 (82\%) were unbooked and 33 (66\%) patients had antepartum eclampsia.

Eleven (22\%) women developed eclampsia related complications. There were $02(4 \%)$ maternal deaths and the common causes were HELLP Syndrome and pulmonary oedema. Neonatal outcome consisted of live births in 39 (78\%) newborns, $03(6 \%)$ were still births, 08 (16\%) were birth asphyxia and 15 (30\%) were low birth weight.

\section{Conclusion}

Majority of the patients were young, illiterate, unbooked primigravidas with poor to average socioeconomic status from rural areas. Majority of the eclamptic women nearly 39 (78\%) cases delivered via caesarean section for better neonatal outcome. Two (4\%) eclamptic women died as a result of eclamptic complications and three $(6 \%)$ newborns had neonatal deaths because of low birth weight and prematurity. Adequate antenatal screening, early detection of hypertension, timely referral, early initiation of treatment and termination of eclamptic patients can help to improve the maternal and perinatal outcomes.

\section{KEYWORDS}

Eclampsia, fetal outcome, maternal outcome 


\section{INTRODUCTION}

Hypertensive disorders in pregnancy are one of the most important causes of maternal and perinatal mortality and morbidity in developing and developed countries. ${ }^{1}$ Nearly $10 \%$ of all the maternal deaths are associated with hypertensive disorders of pregnancy in developing countries. Similarly, perinatal mortality is reported to be $5 \%$ to $11 \%$ in developed countries and $40 \%$ in developing countries. ${ }^{2}$ The incidence of pre-eclampsia and eclampsia is high in developing countries due to hypoproteinemia, malnutrition and poor facilities and underutilization of antenatal care services. ${ }^{1}$

Hypertension is considered as the hallmark for the diagnosis of eclampsia. However, in $16 \%$ cases with eclampsia, hypertension may be absent. ${ }^{3}$ Eclampsia is defined as the development of convulsion and unexplained coma during antepartum/intrapartum/postpartum period in patients with symptoms and signs of pre-eclampsia. ${ }^{4}$ Eclampsia may infrequently be seen in the next 48 hours to 1 month postpartum period (late postpartum eclampsia). Such patients may present with eclamptic fits without ever having manifested signs and symptoms of preeclampsia. ${ }^{5}$

A systemic analysis showed that the incidence of eclampsia ranges from 0 to $0.1 \%$ in Europe, $4 \%$ in Nigeria, $0.6 \%$ in Brazil. ${ }^{6}$ Majority of the cases of eclampsia are seen in young primigravidas and those with no prior antenatal care. ${ }^{4,6}$ The case fatality rate of eclampsia is $1.8 \%$ in developed countries, $17.7 \%$ in India and $13 \%$ in Nepal. ${ }^{7}$

The common causes of maternal deaths in eclampsia are coagulopathy, cerebrovascular haemorrhage, HELLP syndrome, Acute Renal Failure (ARF), aspiration pneumonia, pulmonary oedema, AntePartum Haemorrhage (APH), Postpartum haemorrhage (PPH) whereas perinatal mortality is due to preterm delivery, low birth weight, birth asphyxia and intrauterine growth restriction. ${ }^{2,8}$ HELLP syndrome is a serious complication in pregnancy which is characterized by triad of hemolysis, elevated liver enzymes and low platelet count and occurrs in $10-20 \%$ of cases of severe preeclampsia. ${ }^{9}$

Magnesium sulfate is the drug of choice for treatment of eclamptic fits. WHO has declared magnesium sulphate as the most effective and low cost medication for eclampsia. ${ }^{10}$ Most of the times, maternal magnesium toxicity is clinically monitored by assessing the deep tendon reflexes, respirations and urine output. ${ }^{11}$

The proportion of women surviving severe maternal complications (are also called near-miss cases) has been taken as a useful guide for the evaluation of the quality of maternal health care and its determinants with the potential to complement the information obtained from the reviews of maternal death. ${ }^{9,12}$ However, maternal mortality from eclampsia is decreasing because of early recognition of preeclampsia, specific warning signs and symptoms and termination of at-risk pregnancies in timely fashion. ${ }^{5}$

Eclampsia is one of the dreadful events among the pregnancies complicated with hypertension. Its incidence in the developed and western world has been in decreasing pattern due to improved antenatal care. However, it's still higher in poor and developing countries where adequate antenatal care, early detection of hypertensive disorders and timely referral to a tertiary centre is still lagging. Therefore, it's very important to provide the best possible and the most needed obstetric care and management for improvement of such health conditions in developing countries like ours. Hereby, our study focused on evaluating the maternal and perinatal outcome in cases of eclampsia. This study is needed in our context because no prior similar study on eclampsia is carried out till now which shows that eclampsia is more common among unbooked primi gravidas, from rural area with poor socioeconomic status.

\section{METHODOLOGY}

This was a hospital based cross-sectional study of all eclampsia cases between June 2019- November 2020, conducted at the department of Obstetrics \& Gynecology, Birat Medical College and Teaching Hospital. A total of 50 eclamptic patients were enrolled for the study by total enumeration technique. The objective of the present study was to analyze maternal and perinatal outcome in cases of eclampsia.

All the obstetric cases who developed eclampsia during hospital stay or who were referred with eclampsia and all the newborns delivered to eclamptic mothers or admitted after delivery in cases of postpartum eclampsia were included in the study. Patients with convulsion due to epilepsy, cerebral cause, malaria or any other metabolic cause and those cases of postpartum eclampsia who had delivered outside were excluded from the study.

The study was done after approval by the institutional review committee of Birat Medical College and Teaching hospital (BMCTH). Case records were reviewed from the record section and information were collected and tabulated with respect to the following variables: age, residence, socioeconomic status, education, parity, gestational age, booking status, antenatal blood pressure, antenatal proteinuria, occurrence of fits, number of seizure, mode of delivery, perinatal outcome, maternal complications and mortality, need of maternal ICU and NICU along with postpartum maternal condition till discharge.

Injection magnesium sulphate is the drug of choice and it was used to control convulsions as per the Pritchard regimen along with the stabilization of vitals. In Pritchard regimen, injection magnesium sulphate is given as loading dose of 4 gm IV over 3-5 min followed by 10 gm deep IM (5 $\mathrm{gm}$ in each buttock) and maintenance dose of $5 \mathrm{gm} \mathrm{IM} 4$ hourly in alternate buttock till next 24 hours since last fits. Data was entered in MS excel and analysis was done using IBM SPSS 11. Frequency and percentage were calculated.

\section{RESULTS}

In one and half year duration of study with total number of 6631 deliveries, 50 patients had eclampsia, making an incidence of 7.54/1000 deliveries. Thirty four (68\%) patients 
belonged to $20-30$ years of age group, 10 (20\%) patients were below 20 years and only six (12\%) patients were more than 30 years age. Thirty six (72\%) patients belonged to rural area and 34 (68\%) were illiterate. Fourty nine (98\%) of the cases were from poor to average socioeconomic status and $41(82 \%)$ were unbooked cases. Thirty seven $(74 \%)$ patients were primigravidas and 46 (92\%) patients presented with term pregnancy.

On evaluation of the background characteristics, antenatal blood pressure of 35 (70\%) cases were not known, 14 (28\%) cases were normotensive and one (2\%) case was a known case of hypertension. Antenatal proteinuria was unknown in majority (76\%) of the patients and two (4\%) cases had antenatal proteinuria. Blood pressure during admission was $>140 / 90 \mathrm{mmHg}$ in 40 (80\%) patients whereas 10 (20\%) patients had BP $<140 / 90 \mathrm{mmHg}$. Occurrence of fits during antepartum, intrapartum and postpartum period was observed in 33 (66\%), four (8\%) and 13 (26\%) patients respectively. Single episodes of fits were observed in 39 (78\%) patients whereas 11 (22\%) patients had more than 1

\begin{tabular}{|c|c|c|}
\hline Variables & & $\begin{array}{c}\text { Frequency } \\
\text { (\%) }\end{array}$ \\
\hline \multirow[t]{3}{*}{ Age group (years) } & $<20$ & $10(20.0)$ \\
\hline & $20-30$ & $34(68.0)$ \\
\hline & $>30$ & $06(12.0)$ \\
\hline \multirow[t]{2}{*}{ Residence } & Rural & $36(72.0)$ \\
\hline & Urban & $14(28.0)$ \\
\hline \multirow[t]{3}{*}{ Socioeconomic status } & Poor & $28(56.0)$ \\
\hline & Average & $21(42.0)$ \\
\hline & High & $01(2.0)$ \\
\hline \multirow[t]{2}{*}{ Education } & Literate & $16(32.0)$ \\
\hline & Iliterate & $34(68.0)$ \\
\hline \multirow[t]{2}{*}{ Booking status } & Booked & $09(18.0)$ \\
\hline & Unbooked & $41(82.0)$ \\
\hline \multirow[t]{2}{*}{ Parity } & Primi & $37(74.0)$ \\
\hline & Multipara & $13(26.0)$ \\
\hline \multirow{2}{*}{ Gestational age } & Preterm & $04(8.0)$ \\
\hline & Term & $46(92.0)$ \\
\hline \multirow{3}{*}{$\begin{array}{l}\text { Antenatal } \\
\text { blood pressure }\end{array}$} & Normotensive & $14(28.0)$ \\
\hline & Hypertensive & $01(2.0)$ \\
\hline & Not known & $35(70.0)$ \\
\hline \multirow[t]{3}{*}{ Antenatal proteinuria } & Present & $02(4.0)$ \\
\hline & Absent & $10(20.0)$ \\
\hline & Not known & $38(76.0)$ \\
\hline \multirow{2}{*}{$\begin{array}{l}\text { BP on admission } \\
\text { ( } \mathrm{mm} \text { of } \mathrm{Hg} \text { ) }\end{array}$} & $<140 / 90$ & $10(20.0)$ \\
\hline & $>140 / 90$ & $40(80.0)$ \\
\hline \multirow[t]{3}{*}{ Occurrence of fits } & Antepartum & $33(66.0)$ \\
\hline & Intrapartum & $04(8.0)$ \\
\hline & Postpartum & $13(26.0)$ \\
\hline \multirow[t]{2}{*}{ Episodes of seizure } & Single & $39(78.0)$ \\
\hline & $>$ Once & $11(22.0)$ \\
\hline
\end{tabular}

Majority of the patients i.e, thirty nine (78\%) delivered via emergency lower segment caesarean section for unfavourable cervix and few with fetal distress, nine (18\%) patients delivered spontaneous vaginal delivery and two
(4\%) patients delivered by vaccum assisted vaginal delivery. Regarding maternal complications: four (8\%) patients developed HELLP syndrome, four (8\%) patients had $\mathrm{PPH}$, one $(2 \%)$ patient developed acute renal failure, one (2\%) patient had abruptio placenta, one $(2 \%)$ patient had pulmonary oedema and $39(78 \%)$ patients had none of the complications. About $43(86 \%)$ patients needed ICU admission for further management and the rest of the patients were managed at the obstetrics ward. The health condition of the majority of 48 (96\%) patients was improved before discharge and maternal mortality was observed in two (4\%) patients. Similarly, blood pressure came back to normal in $46(92 \%)$ patients and two (4\%) patients had abnormal blood pressure during discharge. (Table. 2)

Table 2: Demographic profile $(n=50)$
\begin{tabular}{|l|c|c|}
\hline & Maternal outcome & Frequency (\%) \\
\hline Mode of delivery & SVD & $09(18.0)$ \\
\hline & LSCS & $39(78.0)$ \\
\hline $\begin{array}{l}\text { Maternal } \\
\text { complication }\end{array}$ & Anstrumental delivery & $02(4.0)$ \\
\hline & HELLP syndrome & $01(2.0)$ \\
\hline & Abruptio placenta & $01(8.0)$ \\
\hline & PPH & $04(8.0)$ \\
\hline & Pulmonary oedema & $01(2.0)$ \\
\hline ICU admission & None & $39(78.0)$ \\
\hline & Yes & $43(86.0)$ \\
\hline $\begin{array}{l}\text { Condition } \\
\text { at discharge }\end{array}$ & No & $07(14.0)$ \\
\hline & Improved & $48(96.0)$ \\
\hline BP at discharge & Mortality & $02(4.0)$ \\
\hline & Abnormal & $46(92.0)$ \\
\hline
\end{tabular}

*SVD = Spontaneous vaginal delivery

* LSCS = Lower segment caesarean section

*PPH = Post partumhaemorrhage

*ICU= Intensive Care Unit

Among all the newborn babies, live birth was observed in 39 (78\%) babies, three (6\%) babies were stillborn and eight (16\%) had birth asphyxia. Majority of the babies which comprised of 35 (70\%) newborns had normal birth weight appropriate for gestational age and 15 (30\%) newborns had low birth weight $(<2.5 \mathrm{~kg})$ which was more common in preterms. Thirty eight (76\%) babies required NICU admission.

Table 3: Perinatal outcome ( $\mathrm{n=50)}$
\begin{tabular}{|l|l|l|}
\hline \multicolumn{1}{|c|}{$\begin{array}{c}\text { Perinatal } \\
\text { Outcome }\end{array}$} & $\begin{array}{c}\text { Frequency } \\
(\%)\end{array}$ \\
\hline Birth status & Live birth & $39(78.0)$ \\
\hline & Still birth & $03(6.0)$ \\
\hline & Birth Asphyxia & $08(16.0)$ \\
\hline Baby weight & AGA & $35(70.0)$ \\
\hline & LBW & $15(30.0)$ \\
\hline NICU admission & Yes & $38(76.0)$ \\
\hline & No & $12(24.0)$ \\
\hline
\end{tabular}

* AGA= Appropriate for gestational age

* LBW= Low birth weights

* NICU $=$ Neonatal Intensive Care Unit 


\section{DISCUSSION}

The incidence of eclampsia was 7.54/1000 deliveries in our setting which was similar to those in other settings. ${ }^{1,13}$

In the present study, majority of the patients belonged to 20-30 years of age group which was similar to other studies by Aabidha et al. ${ }^{1}$, Kannar et al. ${ }^{4}$ and Shakya et al. ${ }^{14}$ Out of 50 patients, majority of the patients comprising of 37 (74\%) were primigravidas in the present study which was similar to various other studies. ${ }^{14-16}$ Similarly, a hospital based retrospective study had shown eclampsia in $84.60 \%$ primigravidas. ${ }^{7}$ Eclampsia was most commonly seen in pregnant females from the rural area which was similar to a descriptive study at Vellore, India. ${ }^{1}$ Eclampsia was more common among females with poor socioeconomic status in our study which was similar to the study conducted by Silva et al. ${ }^{17}$

Eclampsia was commonest in term pregnancy 46 (92\%) in this study which was similar to the other study findings conducted at a tertiary hospital at Nepal and another study from the UK. ${ }^{7,18}$

The present study showed eclampsia in 34 (68\%) illiterate females. This data was in correspondence to another study conducted by Mahran et al. ${ }^{19}$ where $66.6 \%$ patients didn't receive any education. The incidence of eclamptic convulsions was higher in unbooked cases and this was supported by various other study findings. ${ }^{4,14,15}$

As most patients were unbooked with no ANC visits antenatal blood pressure was not known for most of them. Similar findings were reported by Pannu et al. where blood pressure was unknown in majority of the pregnant women. ${ }^{2}$

The majority of the cases were antepartum eclampsia as observed in $33(66 \%)$ patients in our series. Similarly, antepartum eclampsia was much common in other studies too; $51.2 \%{ }^{15}, 73 \%{ }^{4}, 81.8 \% .^{16}$ In contrast to these, a study in the UK had supported the predominance of postpartum eclampsia (44\%) over antepartum eclampsia. ${ }^{18}$ Intrapartum eclampsia was predominant over antepartum eclampsia in a study by Rayamajhi et al. ${ }^{20}$ Lower incidence of antepartum eclampsia in the developed country may be as a result of better antenatal surveillance and early detection of the disease which lags in poor developing countries like ours.

Majority of the patients accounting for 39 (78\%) patients in the present study delivered via emergency lower segment caesarean section, nine $(18 \%)$ patients by spontaneous vaginal delivery and two (4\%) patients delivered by vaginal assisted instrumental delivery. This was similar to a tertiary hospital study findings at Nepal as reported by Pradhan et al. ${ }^{6}$ In contrast to the present study, Pal et al. in their study had reported majority of the cases delivered vaginally $58.32 \%$ over caesarean section 22.25\%. ${ }^{15}$ Similarly, Murthy et al. had reported a lower incidence $(30.3 \%)$ of caesarean section. ${ }^{16}$ Various reported data showed that many centres liberalised caesarean section for better maternal and fetal outcome.

Maternal complications were observed in 11 (22\%) patients in the present study. The most common maternal complications were postpartum haemorrhage in four (8\%) patients, HELLP syndrome in four (8\%), acute renal failure in one (2\%), abruptio placenta in one $(2 \%)$ and pulmonary oedema in one ( $2 \%$ ) patient. These findings were in contrast to a study by Jido et al. who had reported various maternal complications as HELLP syndrome 4.2\%, acute renal failure 5\%, abruptio placenta $2.5 \%$ and pulmonary oedema $5 \% .{ }^{8}$ Another study had reported various maternal complications as: pulmonary oedema $5.9 \%$ and acute renal failure $8.1 \%$ patients. ${ }^{16}$

Maternal mortality rate in the present study was seen in two (4\%) patients. Similar incidence was reported by various other studies: $5.35 \%{ }^{13}, 8.4 \% .{ }^{16}$ In contrast to these, another study had reported relatively higher incidence of maternal mortality $14 \% .{ }^{4}$ The leading causes of maternal deaths were HELLP syndrome and pulmonary oedema in our study. Different types of complications contribute to the challenge of managing these eclamptic patients with the involvement of different sub-specialities in order to improve their outcome. Those patients who were timely referred to our hospital had early recognition of eclampsia, thereby, helping in reducing the incidence of various maternal complications, morbidity and mortality.

Regarding perinatal outcome, incidence of live births was 39 (78\%), eight (16\%) newborns had birth asphyxia and three (6\%) newborns were stillborn. Perinatal mortality rate varied in different other studies as $20 \%, 21 \%{ }^{20}$ and $27 \%{ }^{13}$ In our study, low birth weight was observed in 15 (30\%) newborns which was similar to other studies: $25.4 \%$, $48.2 \%$. $^{2}$ Low birth weight was most commonly seen in preterm newborns. Risk of severe neonatal birth asphyxia due to late arrival of patients after onset of eclamptic fits were reduced by early referral to our centre with facilities of neonatal intensive care units.

Hypertensive disorders account for the majority of the cases of preterm births, perinatal deaths and intrauterine growth retardation. Higher centers with good neonatal care facilities had comparatively lower incidence of perinatal mortalities.

\section{CONCLUSION}

Majority of the patients were young, illiterate, unbooked primigravida with poor to average socioeconomic status from rural areas. Majority of the eclamptic women accounted for 39 (78\%) cases delivered via caesarean section for better neonatal outcome. Two (4\%) eclamptic women died as a result of eclamptic complications (HELLP syndrome and pulmonary oedema) and three $(6 \%)$ newborns had neonatal deaths because of low birth weight and prematurity.

Adequate antenatal visits, early recognition of the disease, timely referral to higher centers with sub-specialities, early initiation of treatment and termination of eclamptic patients can improve maternal and perinatal morbidity and mortality.

\section{RECOMMENDATIONS}

Eclampsia is a major cause of preventable maternal and perinatal mortality specially in developing countries. Thus, promoting medical education at community level and 
overcoming inconveniences faced during utilization of health care facilities can improve maternal and perinatal outcomes.

\section{LIMITATION OF THE STUDY}

Sample size was small. The lack of proper follow up after hospital discharge limits the analysis of maternal and neonatal outcome for the rest of the puerperium.

\section{ACKNOWLEDGMENT}

I would like to acknowledge my gratitude to all those who helped me in completing this study especially all patients, technical staffs, medical record department, head of the department of obstetrics and gynecology Birat Medical College and Teaching Hospital.

\section{CONFLICT OF INTEREST}

We declare no conflict of interest.

\section{FINANCIAL DISCLOSURE \\ None}

\section{REFERENCES}

1. Aabidha PM, Cherian AG, Paul E, Helan J. Maternal and fetal outcome in pre-eclampsia in a secondary care hospital in South India. J Fam Med Primary Care 2015;4(2):257-60. DOI: 10.4103/2249-4863.154669

2. Pannu D, Das B, Hazari P, Shilpa. Maternal and perinatal outcome in eclampsia and factors affecting the outcome: a study in North Indian population. International Journal of Reproduction, Contraception, Obstetrics and Gynecology. 2014;3(2):347-51. DOI: 10.5455/23201770.ijrcog20140612

3. Katz VL, Farmer R, Kuller JA. Preeclampsia into eclampsia: toward a new paradigm. Am J Obstet Gynecol. 2000;182(6):1389-96. DOI: 10.1067/mob.2000.106178

4. Kannar A, Patel M, Prajapati S, Chavda D. A retrospective study of 100 cases of Eclampsia: perinatal outcomes. Int J ReprodContracept Obstet Gynecol. 2016;5(11):3898-901. DOI: 10.18203/2320-1770. ijrcog20163861

5. Karumanchi SA, Lindheimer MD. Advances in the Understanding of Eclampsia. CurrHypertens Rep. 2008;10(4):305-12. DOI: 10.1007/s11906-008-0057-3

6. Pradhan T, Rijal P, Rai R, Bhatta RD, Thapa BD, Regmi MC. Adverse Maternal and Fetal Outcome in Patients with Eclampsia. J Nepal Health Res Council. 2018;16(41):425-7. DOI: https://doi.org/ 10.33314/jnhrc.1159

7. Choudhary P. Eclampsia : a hospital based retrospective study. Kathmandu University Medical Journal. 2003;1(4):237-41. PMID: 16388262

8. Jido TA. Ecalmpsia: maternal and fetal outcome. African Health Sciences. $2012 ; 12(2): 148-52$. DOl: http://dx.doi.org/ 10.4314/ahs.v12i2.11

9. Chawla S, Marwaha A, Agarwal R. HELLP or Help: A Real Challenge. J ObstetGynaecol India. 2015;63(3):172-5. DOI: 10.1007/s13224014-0582-8

10. Dhakal G, Subedi M, Paudel K. Magnesium Sulphate in Management of Severe Pre-eclampsia and Eclampsia. J Nepal Health Res Council. 2012;10(21):113-7. DOI: 10.1016/0959-289X(92)90027-2

11. Chinayon P. Clinical management and outcome of eclampsia at Rajavithi Hospital. J Med Assoc Thai. 1998;81(8):579-85. PMID: 9737110

12. Abalos E, Cuesta C, Carroli G, Qureshi Z, Widmer M, Vogel JP, Souza JP. Pre-eclampsia, eclampsia and adverse maternal and perinatal outcomes: a secondary analysis of the World Health Organization Multicountry Survey on Maternal and Newborn Health. BJOG 2014; 121(Suppl 1): 14-24. 2014:14-24. DOI: 10.1111/1471-0528.12629

13. Ghimire S. Eclampsia: Feto-Maternal Outcomes in A Tertiary Care Centre in Eastern Nepal. J Nepal Med Assoc. 2016;54(201):24-8. DOI: https://doi.org/10.31729/jnma.2812

14. Shakya B, Vaidya A. Overview of Eclampsia at a Tertiary Care Hospital. Nepal Journal of Obstetrics and Gynaecology. 2014;8(24649). DOI: https://doi.org/10.3126/njog.v8i2.9770

15. Pal A, Bhattacharya R, Adhikari $S$, et al. . Eclampsia-scenario in a hospital- a ten years study. Bangladesh Med Res Counc Bull. 2011;37(2):66-70. DOI:10.3329/bmrcb.v37i2.8437

16. Murthy M, Nigam R, Kujur S. Maternal and perinatal outcome in women with Eclampsia: A retrospective study. International Journal of Medical Research and Review 2016;4(4). DOI: https://doi.org/10.17511/ijmrr.2016.i04.28

17. Silva LM, Coolman M, Steegers EA, et al. . Low socioeconomic status is a risk factor for preeclampsia: the Generation $\mathrm{R}$ Study. the Generation R Study J Hypertens. 2008;26(6):1200-8. DOI: 10.1097/HJH.0b013e3282fcc36e

18. Douglas KA, Redman CW. Eclampsia in the United Kingdom. BMJ. 1994;309(6966):1395-400. DOI: 10.1136/bmj.309.6966.1395

19. Mahran A, Fares H, Elkhateeb R, et al. . Risk factors and outcome of patients with eclampsia at a tertiary hospital in Egypt. BMC Pregnancy Childbirth. 2017;17(1):435. DOI: 10.1186/s12884-0171619-7

20. Rayamajhi AK, Upreti D, Agrawal A, Pokhrel H. Fetomaternal outcome in eclampsia. ournal of Nepal Medical Association, 42(150). 2003;42(150):340-5. DOI: https://doi.org/ 10.31729/ jnma.614 